\title{
A POLÍTICA DE SAÚDE E O SUS NO CENÁRIO CONTEMPORÂNEO: O DESAFIO DO ACESSO E DA ATENÇÃO NA CONJUNTURA NEOLIBERAL
}

\author{
Jovina Moreira Sérvulo Rodrigues (UFPI) ${ }^{1}$
}

\section{RESUMO}

O presente artigo aborda os desafios cotidianos da atenção à saúde no âmbito do SUS, no que se refere ao cuidado. Trata-se de uma análise bibliográfica e documental acerca da importância do acesso a serviços de saúde de qualidade, considerando-se a relevância dos determinantes sociais da saúde, por meio de uma política pública universal e eficaz, num contexto de cortes e congelamento de recursos públicos da saúde, com rebatimento direto na universalidade do SUS. A importância do trabalho reside na necessidade de instigar reflexões acerca das perdas constitucionais e o processo de desconstrução contínua que o Sistema Único de saúde (SUS) vem sofrendo.

Palavras-Chave: Saúde Pública. Determinantes Sociais. Desigualdades territoriais.

\section{ABSTRACT}

This article deals with the daily challenges of health care in the scope of SUS, with regard to care. This is a bibliographic and documentary analysis about the importance of access to quality health services, considering the relevance of social determinants of health, through a universal and effective public policy, in a context of cuts and freezing of resources. public health services, with direct rebound in the universality of the SUS. The importance of the work lies in the need to instigate reflections on the constitutional losses and the process of continuous deconstruction that the Unified Health System - SUS has been suffering.

Keywords: Public health. Social Determinants. Territorial Inequalities.

\section{INTRODUÇÃO}

A temática do artigo retoma a trajetória histórica da saúde, culminando com a relevante conquista de cidadania e defesa da saúde da população, materializadas por meio da política de saúde e do Sistema Único de Saúde (SUS). Concentra-se, também, na discussão sobre a importância do acesso às ações de saúde de qualidade, mas também na importância de que essas ações sejam planejadas e executadas considerando-se os determinantes sociais da saúde em todas as suas acepções, tendo em vista as comprovações de que os elementos da vida social são fundamentais para o alcance de um perfil elevado de saúde e, consequentemente, de defesa da vida.

\footnotetext{
${ }^{1}$ Assistente social especialista em saúde pública pela Universidade de Ribeirão Preto, mestra e doutoranda do Programa de Pós-graduação em Políticas Públicas da Universidade Federal do Piauí (UFPI). Teresina-PI/Brasil. E-mail: jovinamsr@gmail.com. 
ANAIS CBCS 2019 | 3 a 5 de outubro de 2019 | Centro Universitário Santo Agostinho - Teresina - PI

Tratou-se da efetivação da saúde por meio do SUS, na perspectiva da universalidade como um direito de cidadania, em que a CF de 1988 e a Lei 8.080/1990 definem o Estado como o principal responsável pelo processo de organização da política de saúde. Aborda-se, também, a materialização dessa política, da qual os serviços integram os direitos sociais, no âmbito da execução como dependente da ação do Estado, através das políticas sociais.

Contraditoriamente a essa trajetória, instalou-se uma política de desmonte do estado social, através de medidas neoliberais de interesse do capitalismo que, segundo Viana e Silva (2018), vêm se renovando por meio da política de austeridade implantada de forma gradativa no Brasil, sob o discurso da promoção dos direitos sociais, através do Sistema Único de Saúde (SUS). No entanto, diferente desse discurso, a prática das ações contraria a lógica da universalidade do direito à saúde, uma vez que se baseia na focalização das ações (SANTOS; VIEIRA, 2018).

A situação exposta expressa os desafios postos no âmbito da atenção à saúde, na atualidade. Principalmente quanto ao cuidado, na lógica do direito universal, diante do problema do financiamento. Pois, de acordo com Campos (2018) e Paim (2018), embora tenham se passado 30 anos, as ações do SUS ainda não são executadas integralmente, sobretudo, no que se refere aos determinantes sociais da saúde e da necessidade de combate às iniquidades sociais (BUSS; PELLEGRINI-FILHO, 2007).

Assim sendo, o texto está dividido em três itens. O primeiro trata da saúde como política pública e suas limitações, compreendendo o período referente à Reforma Sanitária até a contemporaneidade, pelo qual se faz um breve relato da trajetória histórica da saúde e seus respectivos limites e possibilidades no contexto atual. O segundo item traz uma noção da financeirização do SUS e do aumento das desigualdades sociais. E, por fim, as perspectivas para a sustentabilidade do SUS, nas quais se apresentam as alternativas para promover a concretização do sistema.

\section{METODOLOGIA (Ou MATERIAL E MÉTODOS)}


ANAIS CBCS 2019 | 3 a 5 de outubro de 2019 | Centro Universitário Santo Agostinho - Teresina - P|

O estudo aqui exposto acerca dessa temática, que teve como procedimento metodológico a análise descritiva e exploratória de bibliografias e documentos de referência, originou-se do tema do projeto de doutorado para o qual se realiza estudo da situação da saúde, na perspectiva intersetorial, de um determinado recorte territorial da zona norte de Teresina, capital do Piauí.

\section{A SAÚDE COMO POLÍTICA PÚBLICA E SUAS LIMITAÇÕES: da reforma sanitária à contemporaneidade}

Na década de 1980, o Brasil passa a experimentar novos processos de construção democrática, com novos sujeitos e intensas e amplas discussões sobre as novas condições de vida, após superado o regime da ditadura militar, mesmo diante do profundo e amplo processo de crise que, perpassados todos os períodos históricos, permanece até a atualidade, e das decepções com o processo democrático, cuja transição não superou o conservadorismo (BRAVO, 2001).

Nesse período, iniciam-se as manifestações originárias da Reforma Sanitária, que se constituiu num emblemático movimento, no âmbito da saúde coletiva, de luta pela ampliação do debate teórico e pela incorporação de temáticas específicas, entre as quais o Estado e as políticas sociais, fundamentadas na doutrina marxista. Esse movimento, conhecido também como Movimento Sanitário ou Movimento pela Democratização da Saúde, foi organizado com o objetivo de enfrentar a problemática instalada; defender a democratização da saúde e alcançar a reestruturação da rede de serviços, contando com a participação de diversos segmentos, principalmente populares, estudantis, pesquisadores, instituições acadêmicas e sociedade científica (PAIM, 2013).

A 8a Conferência Nacional de Saúde, evento de relevância histórica para o país, impulsionado pela Reforma Sanitária, proporcionou a concretização do conceito de saúde como um direito do cidadão, e o desenho da fundamentação do SUS, além de propiciar o desenvolvimento de caminhos referentes à coordenação, integração e transferência de recursos entre as instituições das três esferas de governo, que representaram iniciativas cruciais para a construção do SUS (PAIM, 2018). 
ANAIS CBCS 2019 | 3 a 5 de outubro de 2019 | Centro Universitário Santo Agostinho - Teresina - P|

Segundo Matos (2014), o SUS representou um importante avanço, considerando-se todo o seu contexto histórico. Contudo, não foi implantado na sua integralidade, e esse pressuposto tornase mais evidente, quando comparado à saúde existente no período da ditadura militar. Para esse autor, a não concretização dos princípios e diretrizes do sistema, assim como as demais limitações existentes, que impediram a concretização do pensamento reformador, fizeram do SUS um sistema inconcluso e distante do que versa o movimento de reforma sanitária.

De acordo com Campos (2018), a implementação parcial do SUS pode ser a resposta para o conformismo em relação ao desmonte que o sistema vem sofrendo na atualidade. Ressalta que houve uma expressiva expansão do SUS no âmbito do acesso à Atenção Básica, às urgências, às vacinas, ao pré-natal, a serviços especializados e hospitalares. Mas, contraditoriamente, esse sistema de saúde se apresenta como o principal problema do país. O autor pontua, ainda, que o SUS, em sua completude, traduz-se na expressão máxima da política de saúde do país, representada por meio dos benefícios para a população. Assim como a "sua debilidade é também o SUS realmente existente, com todas as suas mazelas e insuficiências" (CAMPOS, 2018, p. 1710).

Nessa perspectiva, o panorama do Sistema Único de Saúde revela os retrocessos que o sistema tem apresentado, a partir de medidas que alteraram sua concepção original. No contexto político do período de 1995 a 2002, por exemplo, a saúde se pautou nos princípios da contrarreforma de Estado, a ponto de promover a retomada do sanitarismo campanhista; do desrespeito à participação social; da regulamentação dos planos privados de saúde; da proliferação de ações realizadas por meio do PAC/PSF - em vista do financiamento vertical contido na NOB/96 - e da criação de agências reguladoras, concebidas sob um formato contraditório à lógica do SUS (MATOS, 2014).

Adensando a discussão acerca da regulamentação dos planos de saúde, Viana e Silva (2018) apontam essa situação como integrante do processo de financeirização da proteção social, que se revela na tensão existente entre a ideia de saúde como direito, bem coletivo universal ou bem público universal, e a saúde como bem econômico e individual. Segundo esses autores, trata-se do processo de desresponsabilização do Estado com a saúde dos cidadãos, delegando a esses a função 
ANAIS CBCS 2019 | 3 a 5 de outubro de 2019 | Centro Universitário Santo Agostinho - Teresina - P|

de únicos responsáveis pela sua saúde individual e os respectivos riscos aos quais se tornam sujeitos nas diversas situações a que ficam expostos, além de se tornarem reféns de inúmeros mecanismos de compra de serviço.

De fato, a atual configuração da política de saúde no Brasil, baseada no ideal da democracia, engendrou novos parâmetros de ação, legitimados com o advento da Constituição de 1988, cujo formato de atenção se traduz na concretização do conceito ampliado de saúde. Sendo também ampliado quanto à lógica da atenção, baseada no direito de cidadania universal, rompendo com a lógica de atenção que, anteriormente, não compreendia todos os estratos sociais.

No entanto, o direito universal à saúde, como conquista e garantia constitucional, encontrase em risco, na medida em que se assiste a uma gradual retirada do Estado do campo das suas obrigações, não de uma forma que se possa concretamente identificar, como diz Mendes (2017), mas de um modo associado à dinâmica do capital, como parte da lógica neoliberal, em que o capital financeiro prevalece e o Estado brasileiro segue concedendo incentivo à iniciativa privada.

Mendes (2017) assinala que refletir sobre os ataques à universalidade da saúde, nas últimas décadas, remete a uma articulação com o capitalismo, na perspectiva da financeirização no contexto da crise contemporânea. Nesse cenário, verifica-se, portanto, o aumento dos ataques aos direitos sociais e à saúde na forma das políticas austeras.

Independente de representar um corte expressivo nos gastos públicos, as políticas austeras, que compreendem medidas integrantes da lógica neoliberal recém-adotadas como parte das mudanças de organização do sistema de proteção social, servindo aos interesses mercantis, compreendem os vários aspectos que vêm promovendo o enfraquecimento da capacidade de arrecadação do Estado brasileiro e prejudicando, dessa forma, o financiamento do SUS (MENDES, 2016).

De acordo com Sposati (2018), o processo de retração financeira atinge as três políticas que integram a seguridade social. Esse autor afirma que apesar de ter representado uma grande inovação para o país, atualmente, vem sendo diluída e afastada para o campo privado filantrópico 
ANAIS CBCS 2019 | 3 a 5 de outubro de 2019 | Centro Universitário Santo Agostinho - Teresina - P|

e perdendo seu componente democrático e republicano, descaracterizando a proteção social da sua condição de direito universal.

Na saúde pública, neste cenário globalizado, as condições de vida e de saúde têm melhorado, a julgar pelos fatores condicionantes e determinantes da saúde ao longo desta última década do século XXI, cuja pesquisa realizada por Conill et al. (2018) comprova que essa evolução ocorreu, principalmente, na Argentina e no Brasil.

Paradoxalmente a esses indícios de crescimento, segue em andamento o desmonte do estado social, pelas vias da política neoliberal, sob a retórica da implantação de um conjunto de medidas destinado ao atendimento da coletividade (VIANA; SILVA, 2018), e, mais recentemente, à política de austeridade implantada no Brasil, que, também, por meio da retórica da garantia do direito social universal, do foco no financiamento do Sistema Único de Saúde (SUS) e no direito à saúde tem produzido implicações que resvalam no crescimento das desigualdades. Pois, a dimensão universal apregoada na prática desse modelo não atinge toda a população, caracterizando-se, portanto, em ações baseadas no viés focalista (SANTOS; VIEIRA, 2018).

Neste sentido, ressaltam-se os expressivos desafios da atenção à saúde, na atualidade, sobretudo no que se refere ao cuidado na perspectiva do direito universal, face à problemática do financiamento, pois se vive numa realidade em que as ações do SUS, apesar dos seus 30 anos de existência, ainda não são executadas integralmente (CAMPOS; PAIM, 2018), com base nos padrões de reconhecimento dos determinantes sociais da saúde e da respectiva necessidade de combate às iniquidades geradas por esses fatores determinantes (BUSS; PELLEGRINI-FILHO, 2007).

\section{SAÚDE E DESIGUALDADE SOCIAL}

A importância e a necessidade do acesso a serviços médico-assistenciais de qualidade são imprescindíveis. Contudo, é importante assinalar que a concepção e o tratamento dos determinantes da saúde, em todas as suas acepções, exigem a atuação de políticas públicas 
ANAIS CBCS 2019 | 3 a 5 de outubro de 2019 | Centro Universitário Santo Agostinho - Teresina - P|

coerentes, por meio de uma efetiva articulação intersetorial do poder público, além da mobilização popular (BUSS, 2000).

O processo discursivo acerca das desigualdades sociais em saúde (DSS) ganhou espaço na agenda cotidiana da sociedade no século XX, a partir do quadro das expressivas desigualdades manifestadas nos diversos espaços territoriais cujas repercussões impactam em todas as áreas de abrangência da vida da população, tais como: condições de vida; disparidades sociais nos padrões de saúde-doença e no acesso à atenção à saúde dos indivíduos.

Acerca da similaridade das cidades brasileiras no que se refere à desigualdade sócioterritorial, Koga $(2015$, p. 13) registra: [...] "e nesse ponto é que as cidades brasileiras se tornam parecidas, apresentando cada qual pedaços de chãos que conformam um mosaico de condições de vida extremamente discrepantes entre seus moradores, em que somente alguns são considerados cidadãos, e outros cidadãos de segunda categoria".

Koga (2015, p. 11) cita que o texto introdutório da Política Nacional de Saúde orienta que as intervenções em saúde ampliem seu escopo, observando-se os problemas e as necessidades de saúde, assim como seus determinantes e condicionantes, "de modo que a organização da atenção e do cuidado envolva, ao mesmo tempo, as ações e os serviços que operem sobre os efeitos do adoecer e aqueles que visem ao espaço para além dos muros das unidades de saúde e do sistema de saúde".

De acordo com Fleury (2012), a Declaração de Alma Ata, em 1978, representou uma importante iniciativa para ampliar as discussões sobre os DSS e minimizar o problema das disparidades sociais, por meio da promoção da equidade no acesso à saúde, por meio da adoção da estratégia de Atenção Primária em Saúde (APS), ressaltando, no entanto, que "essa estratégia de atenção à saúde deveria se articular dentro de uma abordagem abrangente, que tivesse em conta as causas sociais, econômicas e políticas dos problemas de saúde, o protagonismo das políticas sociais e de saúde" (FLEURY, 2012, p. 02).

Porém, anos após a publicação da Declaração de Alma-Ata e seus desdobramentos, incluindo-se a proposta da APS, Fleury (2012) registra que as discussões sobre os determinantes 
ANAIS CBCS 2019 | 3 a 5 de outubro de 2019 | Centro Universitário Santo Agostinho - Teresina - P|

sociais da saúde se fragilizaram, como repercussão das medidas do neoliberalismo, cujo conteúdo compreendia desde a perspectiva reducionista da ação pública à provisão focalizada de pacotes de atenção básica destinada aos mais vulneráveis. No entanto, essas discussões sobre os determinantes sociais da saúde são retomadas logo que se constatou sobre o fracasso das políticas focalizadas na redução da pobreza e das desigualdades.

Segundo Campos (2018), o acesso à saúde, na perspectiva universal, encontra-se comprometido, devido às medidas restritivas do receituário neoliberal, cuja implicação se destina a enfraquecer e reduzir a amplitude do SUS no âmbito da cobertura populacional e dos serviços prestados. Segundo esse autor, as recomendações desse citado receituário compreendem privatização, terceirização, parceria público-privada, descentralização com desregulação e fragmentação da rede, fim da gratuidade.

Segundo a percepção de Alves (2012), os diferentes formatos de convívio e relacionamento das pessoas em sociedade refletem, de modo significativo, nas suas condições de saúde. Ressalta, ainda, que a saúde, se concebida sob a perspectiva das necessidades básicas dos seres humanos, como um meio de se conviver de forma digna, remete ao entendimento de que o processo saúdedoença está vinculado à determinação social sob a égide da cidadania. Consoante esse entendimento, essa autora menciona que a própria Organização Mundial da Saúde (OMS) tem fundamentado seus estudos e concepções no entendimento de que a análise da saúde deve perpassar os determinantes biológicos, tais como idade, fisiopatologia, fatores genéticos etc.

No âmbito da efetivação da saúde como direito de cidadania, a CF de 1988 e a Lei 8.080/1990 definem o Estado como o principal responsável pelo processo de organização da política de saúde. E a materialização dessa política, da qual os serviços integram os direitos sociais, depende da ação do Estado, através das políticas sociais.

No entanto, cabe assinalar que essas ações estão cada vez mais ineficazes e insuficientes, devido a problemas de ordem do financiamento oriundos da conjuntura, de crises e de ajustes em vigor. Dessa forma, a efetivação das próprias ações de saúde pública, nesse contexto de restrição 
ANAIS CBCS 2019 | 3 a 5 de outubro de 2019 | Centro Universitário Santo Agostinho - Teresina - P|

do papel do Estado e de fortalecimento do mercado, que corroboram com a ampliação das desigualdades no atendimento, constitui-se num dos principais desafios da atualidade.

Portanto, observa-se que neste contexto de supremacia do capital financeiro, os ajustes neoliberais estabelecidos se revelam como uma realidade de arrocho financeiro presente, principalmente, pela redução da ação do Estado em suas respostas aos problemas sociais da coletividade. Dessa forma, a sociedade padece com os retrocessos sofridos em decorrência dessa lógica mercantil cujos rebatimentos têm repercussão direta nas conquistas de cidadania.

\section{CONSIDERAÇÕES FINAIS/CONCLUSÕES}

A discussão sobre a origem e trajetória histórica da saúde no Brasil consiste em retomar um período em que o acesso à saúde era determinado pela classe social a que pertenciam as pessoas, considerando-se que os ricos acessavam facilmente os serviços médicos, o que não ocorria com os pobres, que ficavam à mercê da filantropia e da caridade, cujas instituições religiosas, como as Santas Casas de Misericórdia, eram a opção para essa parcela da população desfavorecida da situação vigente.

E, de uma forma mais próxima, remete ao panorama social da década de 1980 , no qual a maior parte dos cidadãos era excluída do direito à saúde, que se materializava na assistência prestada pelo Instituto Nacional de Previdência Social, restrita à parcela dos trabalhadores que contribuía, baseada na cidadania regulada (SANTOS, 1979).

No entanto, o Movimento de Reforma Sanitária e a VIII Conferência Nacional de Saúde trouxeram uma nova realidade para a população, por meio do Sistema Único de Saúde (SUS), fundamentada pela Constituição Federal de 1988 e regulamentada pelas Leis Federais no 8.080 e no 8.142, de 1990, que dispõem, respectivamente, sobre a organização e regulação das ações de saúde e sobre financiamento da saúde e da participação popular.

Nesse contexto, ressalta-se que o reconhecimento dos determinantes sociais da saúde representa um salto qualitativo importantíssimo nesse processo de construção, cuja abrangência do conceito da saúde e da intersetorialidade implicaram na valorização das comprovações 
ANAIS CBCS 2019 | 3 a 5 de outubro de 2019 | Centro Universitário Santo Agostinho - Teresina - PI

científicas, no comprometimento com a ação, bem como na adoção de políticas intersetoriais ${ }^{2}$, cuja importância se revela, também, na defesa da saúde como direito, ao propiciar amplas articulações em espaços compartilhados de decisões interinstitucionais e intergovernamentais que impactam positivamente na saúde da população (PAIM, 2009).

A partir desse avanço, estudos, pesquisas e práticas passaram a dar credibilidade às dimensões históricas, políticas e sociais no âmbito das vivências individuais e coletivas. E a reconhecer que a relação existente entre as mazelas sociais produzidas pela pobreza, desigualdade e exclusão social torna os indivíduos vulneráveis às doenças (ALVES, 2012).

De acordo com Bravo (2001), o projeto da saúde consolidou-se, embora tenha favorecido ao mercado, visto que as políticas que compõem o tripé da seguridade social foram implantadas na conjuntura da contrarreforma, fato promotor do distanciamento entre as políticas de Seguridade da proposta do Congresso Constituinte e das leis complementares, contrariamente à concepção de Paim (2013).

Na concepção de Paim (2009), a Constituição de 1988, ao estabelecer que a assistência era livre à iniciativa privada, cabendo ao poder público promover, nos termos da lei, sua regulamentação, fiscalização e controle, podendo ser executada diretamente ou indiretamente, via pessoa física ou jurídica de direito privado, propiciou a incerteza quanto à sua definição, ao questionar se a saúde é um bem público ou um serviço que pode ser comercializado.

Bravo (2001) aponta que apesar dos avanços alcançados há uma distância entre o SUS real e o SUS constitucional. Assim também ocorre entre o movimento de reforma sanitária e a prática social do sistema público em vigor. De acordo com a Constituição, o SUS é um sistema universal, que, na realidade, vem atendendo, em sua maioria, os cidadãos que não têm acesso aos sistemas privados de saúde.

Não resta dúvida de que o SUS representou um importante avanço, considerando-se todo o seu contexto histórico. Contudo, não foi implantado na sua integralidade, e esse pressuposto se torna mais evidente quando comparado à saúde existente no período da ditadura militar. Portanto, a não concretização dos princípios e diretrizes do sistema, assim como as demais limitações

\footnotetext{
${ }^{2}$ Consiste num complexo mecanismo de política pública que visa a superar a fragmentação das políticas sociais nos diversos segmentos (PAIM, 2009). 
ANAIS CBCS 2019 | 3 a 5 de outubro de 2019 | Centro Universitário Santo Agostinho - Teresina - P|

existentes, que impediram a concretização do pensamento reformador, fizeram do SUS um sistema inconcluso e distante do que versa o movimento de reforma sanitária (MATOS, 2014).

Nessa direção, observa-se que a proposta da Política de Saúde construída na década de 1980 tem sido desconstruída. Os serviços de saúde se encontram vinculados ao mercado, enquanto que se identificam ações e serviços realizados por meio das parcerias com a sociedade civil que, por sua vez, têm sido responsabilizadas pelos custos da crise.

O caráter da universalidade e a relação público-privado estão legitimados na Constituição de 1988 para todas as políticas públicas setoriais. Destaca-se, a partir desse aspecto, a contradição central das políticas públicas vigentes, pois o SUS é para todos, mas o processo de financeirização ao qual vem sendo submetido tem comprometido o princípio da universalidade, no sentido de construir, no imaginário da sociedade, a concepção de que os serviços do SUS devem se destinar ao público menos favorecido, marcando o distanciamento entre o sistema e a política universal.

\section{REFERÊNCIAS}

ALVES, H. Avanços e desafios do programa bolsa família na perspectiva da determinação social em saúde. In: Acta scientiae médica, 2012.

BUSS, P. M. Promoção da saúde e qualidade de vida. In: Ciência e Saúde Coletiva, Rio de Janeiro, v. 5, n. 1, p. $163-177,2000$.

BUSS, P. M.; PELLEGRINI FILHO, A. A saúde e seus determinantes sociais. In: Physis, Rio de Janeiro, v. 17, n. 1, abr. 2007.

BRAVO, M. I. S. A Política de Saúde no Brasil: trajetória histórica. In: Capacitação

para Conselheiros de Saúde: textos de apoio. Rio de Janeiro: UERJ/DEPEXT/NAPE, 2001.

CAMPOS, G. W. de S. SUS: o que e como fazer? In: Ciência \& Saúde Coletiva, Rio de Janeiro, v. 23, n. 6, 2018.

CONNIL, E. M. et al. Saúde e qualidade de vida: o desafio contemporâneo do cuidado e da atenção na conjuntura neoliberal. In: Ciência \& Saúde Coletiva, Rio de Janeiro, v. 23, n. 7, 2018.

FLEURY, S. Desigualdades injustas: o contradireito à saúde. In: Cebes, Fundação Getúlio Vargas, Rio de Janeiro, Brasil, 2012. 


\section{CONGEESSOC CIENCIAESOCIEDADE

ANAIS CBCS 2019 | 3 a 5 de outubro de 2019 | Centro Universitário Santo Agostinho - Teresina - PI

KOGA, D. Territórios de vivência em um país continental. In: Serv. Soc. \& Saúde, Campinas, SP, v. 14, n. 1(19), 2015.

MATOS, M. C. de. No rastro dos acontecimentos: política de saúde no Brasil. In: DUARTE, M. J. de O. et al. Política de Saúde hoje: interfaces \& desafios no trabalho de assistentes sociais. Campinas, SP: Papel Social, 2014.

MENDES, Á. A saúde pública brasileira num universo "sem mundo": a austeridade da Proposta de Emenda Constitucional 241/2016 In: Cad. Saúde Pública, v. 32, n. 12, Rio de Janeiro, 2016.

MENDES, Á. A saúde no capitalismo financeirizado em crise: o financiamento do SUS em disputa. In: Futuro do Brasil ideia para ação, 2017.

PAIM, J. S. O que é o SUS. Rio de Janeiro: Editora Fiocruz, 2009.

PAIM, J. S. Sistema Único de Saúde (SUS) aos 30 anos. In: Ciência \& Saúde Coletiva, Rio de Janeiro, v. 23, n. 6, 2018.

SANTOS, I. S.; VIEIRA, F. S. Direito à saúde e austeridade fiscal: o caso brasileiro em perspectiva internacional. In: Ciência \& Saúde Coletiva, Rio de Janeiro, v. 23, n. 7, 2018.

SANTOS, W. G. Cidadania e Justiça: a Política Social na Ordem brasileira. Rio de Janeiro: Campus, 1979.

SHERER, M. D. dos A. dos et ali. Desafios para o trabalho em saúde: um estudo comparado de Hospitais Universitários na Argélia, Brasil e França. In: Ciência \& Saúde Coletiva, Rio de Janeiro, v. 23, n. 7, 2018.

SPOSATI, A. Descaminhos da seguridade social e desproteção social no Brasil. In: Ciência \& Saúde Coletiva, Rio de Janeiro, v. 23, n. 7, 2018.

VIANA, A. L. Á.; SILVA, H. P. da. Meritocracia neoliberal e capitalismo financeiro: implicações para a proteção social e a saúde. In: Ciência \& Saúde Coletiva, Rio de Janeiro, v. 23, n. 7, 20. 